\begin{tabular}{|l|l|l||}
\hline \multicolumn{2}{|c|}{ PublisherInfo } \\
\hline \hline PublisherName & $:$ & BioMed Central \\
\hline \hline PublisherLocation & $:$ & London \\
\hline \hline PublisherImprintName & $:$ & BioMed Central \\
\hline \hline
\end{tabular}

\title{
Normocapnic ventilation at low tidal volumes in man
}

\begin{tabular}{|l|l|l||}
\hline \multicolumn{2}{|c||}{ ArticleInfo } \\
\hline \hline ArticleID & $:$ & 4088 \\
\hline \hline ArticleDOI & $:$ & $10.1186 /$ ccf-1999-1361 \\
\hline \hline ArticleCitationID & $:$ & 1361 \\
\hline \hline ArticleSequenceNumber & $:$ & 25 \\
\hline \hline ArticleCategory & $:$ & Paper Report \\
\hline \hline ArticleFirstPage & $:$ & 1 \\
\hline \hline ArticleLastPage & $:$ & 3 \\
\hline \hline & & RegistrationDate : 1999-8-13 \\
\hline ArticleHistory & $:$ & OnlineDate \\
\hline \hline ArticleCopyright & $:$ & Current Science Ltd1999-8-13 \\
\hline \hline ArticleGrants & $:$ & \\
\hline \hline ArticleContext & $:$ & 130541111 \\
\hline \hline
\end{tabular}




\section{Keywords}

Barotrauma, dead space, mechanical ventilation

\section{Comments}

The prevention of volutrauma by using low tidal volume ventilation and permissive hypercapnia has been shown to reduce mortality. ASPIDS may offer the physician further help in achieving this goal, and this study shows that it is feasible in the ICU. ASPIDS now needs to be investigated for prolonged periods in the population for which it is intended (those with severe lung disease), and if it is shown to be a useful device for everyday clinical use, it requires development.

\section{Introduction}

Protective ventilatory strategies for patients with severe pulmonary pathology include low tidal volume ventilation, resulting in permissive hypercapnia. Carbon dioxide clearance may be improved however, by aspiration of dead space (ASPIDS) and instillation of fresh gas during the expiratory cycle. Consequently it may be possible to ventilate with low tidal volumes and still maintain normocapnia.

\section{Aims}

To investigate whether ASPIDS allows low tidal volume ventilation withnormocapnia, and also whether increased respiratory rates may allowfurther reductions in tidal volume as a consequence of improved carbondioxide clearance.

\section{Methods}

Seven ventilated patients on the neurointensive care unit were investigated using a Servo ventilator 900 (Siemens-Elma, Sweden) with ASPIDS and instillation of fresh gas controlled by an IBM 
compatible computer (see paper). Following baseline measurements of mechanics and blood gases made at a respiratory rate decided by the attending physician (mean 12.6 breaths/min), ASPIDS was commenced with minute ventilation reduced by a factor of "tubing dead space X respiratory rate". The respiratory rate was then increased to 20 breaths/min with the minute ventilation adjusted to maintain normocapnia, and the measurements were repeated. The time period of the whole study was under one hour.

\section{Results}

No adverse events were experienced with ASPIDS. Tidal volume was reduced from $602 \pm 77 \mathrm{ml}$ to $456 \pm 76 \mathrm{ml}$ during ASPIDS, with a significant reduction in airway pressures, at the baseline rate of 12.6 breaths/min. At 20 breaths/min blood gases were equivalent to those at 12.6 breaths $/ \mathrm{min}$, but during ASPIDS tidal volumes were reduced even further from $429 \pm 74 \mathrm{ml}$ to $305 \pm 43 \mathrm{ml}$

\section{Discussion}

ASPIDS (produced by the computer driven ventilator used in this study) allows reductions in tidal volumes and airway pressures without hypercapnia. Furthermore by using ASPIDS at higher respiratory rates, even lower tidal volumes can be utilised. The authors comment that their system for ASPIDS requires modifications prior to becoming commercially available. However they have shown that ASPIDS is possible in the ICU and has the potential for being a very useful manoeuvre when adopting protective ventilation strategies.

\section{References}

1. De Robertis E, Servillo G, Jonson B, Tufano R: Aspiration of dead space allows normocapnic ventilation at low tidal volumes. Intensive Care Med. 1999, 25: 674-679.

This PDF file was created after publication. 